\title{
ANTIDIABETIC EFFECTS OF [10]-GINGEROL IN STREPTOZOTOCIN- AND HIGH-FAT DIET-INDUCED DIABETIC RATS
}

\author{
ASHUTOSH KUMAR YADAV*, REETU, ARUN GARG \\ Department of Pharmacology, K.R. Mangalam University, Gurgaon, India. Email: ashutoshyadava@gmail.com
}

Received: 21 August 2019, Revised and Accepted: 16 September 2019

\begin{abstract}
Objective: India is the "diabetes capital of the world" with 62.4 million Indians having type 2 diabetes in 2011. A major risk factor for insulin resistance is obesity, which is generally caused by regular physical inactivity and high-fat diet (HFD). Obesity and diabetes are closely related to each other as about $80 \%$ of diabetics are obese. Obesity is a common finding in type 2 diabetes. The objective of the study was to investigate the antidiabetic effects of [10]-gingerol in streptozotocin (STZ)- and HFD-induced diabetic rats.
\end{abstract}

Methods: Wistar rats were used for the study. Animals were divided into six groups. The six groups in this study were, Group I (normal control), Group II (diabetic control), Group III (glibenclamide at $5 \mathrm{mg} / \mathrm{kg}$ p.o.), Group IV (orlistat at $60 \mathrm{mg} / \mathrm{kg}$ p.o.), Group V ([10]-gingerol at 15 mg/kg p.o.), and Group VI [10]-gingerol (30 mg/kg p.o.), respectively. The antidiabetic activity was assessed using blood glucose level, body weight, and various biochemical parameters such as serum total cholesterol (TC) level, triglyceride (TG) level, high-density lipoproteins (HDLs), total protein (TP), serum alanine transaminase, and aspartate aminotransferase (serum glutamic-oxaloacetic transaminase), respectively.

Results: [10]-gingerol exhibited an antidiabetic effect by significantly decreased the level of blood glucose, body weight, TC, TG, TP, and increase HDL. The results of the study demonstrated that the treatment with [10]-gingerol significantly $(p<0.05)$ and dose dependently prevented STZ- and HFD-induced diabetic rats.

Conclusions: The findings of the study suggest that [10]-gingerol possesses potential antidiabetic activity as it lowers serum glucose level.

Keywords: [10]-gingerol, Diabetes, High-fat diet, Streptozotocin.

(C) 2019 The Authors. Published by Innovare Academic Sciences Pvt Ltd. This is an open access article under the CC BY license (http://creativecommons. org/licenses/by/4. 0/) DOI: http://dx.doi.org/10.22159/ajpcr.2019.v12i11.35421

\section{INTRODUCTION}

The occurrence of type 2 diabetes mellitus is rapidly rising around the world's population. India is the "diabetes capital of the world" with 62.4 million Indians having type 2 diabetes in 2011 [1]. Blood glucose level was increased in type 2 diabetes mellitus due to a progressive decline in insulin action (insulin resistance) and pancreatic $\beta$-cell dysfunction [2]. A major risk factor for insulin resistance is obesity, which is generally caused by regular physical inactivity and high-fat diet (HFD) [3]. Obesity and diabetes are closely related to each other as about $80 \%$ of diabetics are obese. Obesity is a common finding in type 2 diabetes. There is impaired insulin sensitivity of peripheral tissues such as muscle and fat cells to the action of insulin in obese individuals (insulin resistance). The reduction of weight in obese patients produces an enhancement in diabetic state [4]. Obesity increases the risk of type II diabetes, cardiovascular disease, cancer, and premature death [5]. A pharmacological factor involved in obesity and diabetes includes lipoprotein lipase (LL), having a central role in the metabolism of both triglyceride (TG)-rich particles and high-density lipoproteins (HDLs). LL is determinant of serum TG and HDL concentrations [6]. The influence of obesity on type 2 diabetes risk is determined not only by the amount of obesity but also by fat deposition [7].

The current treatment for type 2 diabetes includes insulin and oral hypoglycemic drugs, i.e., sulfonylurea derivatives, thiazolidinediones, biguanides, and $\alpha$-glucosidase inhibitors, but these medications have most of the side effects. Many traditional plant remedies for obesity and diabetes are used throughout the world. Ginger, the rhizome of the Zingiber officinale is commonly consumed dietary condiments. Ginger and its constituents show antioxidant activity and prevent the damage of macromolecules, caused by the free radicals/oxidative stress [8]. The compounds derived from natural sources, which are considered to be safe and cost effective, are needed. Ginger is one of the most widely used natural products consumed as a spice and medicine for treating nausea, dysentery, diabetes, heartburn, flatulence, diarrhea, loss of appetite, infections, cough, and bronchitis. Experimental studies showed that its active components [10]-gingerol exert antidiabetic effects against streptozotocin (STZ)- and HFD-induced diabetic rats.

\section{METHODS}

\section{Animals}

Wistar rats (150-200 g) were group housed ( $\mathrm{n}=6)$ under a standard $12 \mathrm{~h}$ light/dark cycle and controlled conditions of temperature and humidity $\left(25 \pm 2^{\circ} \mathrm{C}, 55-65 \%\right)$. Rats received standard rodent chow and water ad libitum. Rats were acclimatized to laboratory conditions for 7 days before carrying out the experiments. All the experiments were carried in a noise-free room between 08.00 and $15.00 \mathrm{~h}$. A separate group ( $\mathrm{n}=6)$ of rats was used for each set of experiments. The animal studies were approved by the Institutional Animal Ethics Committee, constituted for the Purpose of Control and Supervision of Experimental Animals by the Ministry of Environment and Forests, Government of India, New Delhi, India.

\section{Drugs and chemicals}

[10]-gingerol (Sigma-Aldrich) and STZ (Sigma-Aldrich) were used in the present study. All other chemicals and other biochemicals used in the experiments were of analytical grade from different firms.

Experimental design and treatment protocol

After 28 days of administration of HFD, the rats were injected intraperitoneally by a single dose of a prepared solution of STZ (30 $\mathrm{mg} \mathrm{kg}$ suspended in $0.1 \mathrm{~mol} / \mathrm{L}$ citrate buffer at $\mathrm{pH} 4.5$ ). If the fasting blood glucose was more than $300 \mathrm{mg} / 100 \mathrm{ml}$ after $72 \mathrm{~h}$ of STZ injection, 
the diabetic type 2 models were successful. Approximately $200 \mu \mathrm{l}$ blood was collected from each animal by retro-orbital sinus in $0.5 \mathrm{ml}$ Eppendorf tubes containing $20 \mu \mathrm{l}$ of $20 \%$ sodium fluoride solution. The collected blood was centrifuged at $8000 \mathrm{rpm}$ at temperature $18-22^{\circ} \mathrm{C}$ for $10 \mathrm{~min}$ by centrifuge machine. All animals were weighed, randomized, and divided into six groups (six animals each) and were given the following treatment for 21 days by oral route [9].

- Group I - Normal

- Group II - Diabetic rats received only distilled water (negative control)

- Group III - Diabetic rats were treated with glibenclamide (5 mg/kg p.o.)

- Group IV - Diabetic rats received orlistat (60 mg/kg/day p.o.)

- Group V - Diabetic rats received [10]-gingerol (15 mg/kg/day p.o.)

- Group VI - Diabetic rats received [10]-gingerol (30 mg/kg/day p.o.)

At the end of the $21^{\text {st }}$ day treatment, i.e., $24 \mathrm{~h}$ after the last dose of the drug and standard drugs, the rats were anesthetized and blood was collected by retro-orbital plexus followed by heart puncture and allowed to clot. After blood withdrawal, animal was sacrificed. The serum was separated by centrifugation at $3000 \mathrm{rpm}$ at $4^{\circ} \mathrm{C}$ for $20 \mathrm{~min}$ for the analysis of various biochemical parameters.

\section{Biochemical evaluation in serum}

Serum total cholesterol (TC) level, TG level, HDL, total protein (TP), serum alanine transaminase (SGPT), and aspartate aminotransferase (serum glutamic-oxaloacetic transaminase [SGOT]) were determined using standard kits from Transasia Bio-Medicals Limited, Mumbai, India. The estimation procedure is obtained in detail from leaflets provided by the commercially available kits which are as follows:

\section{Histopathology}

The formalin-fixed tissue pieces from pancreas were serially dehydrated in alcohol and cleared in xylene and were embedded in paraffin blocks. The microsections (4-5 microns thick) were cut and stained in hematoxylin and eosin using the standard method and examined for histopathological changes.

\section{Statistical analysis}

All statistical analyses are expressed as the mean \pm standard error of the mean. Data were analyzed by one-way ANOVA, where applicable $\mathrm{p}<0.05$ was considered statistically significant, compared with vehicle followed by Dunnett's test.

\section{RESULTS AND DISCUSSION}

Effect of [10]-gingerol on body weight in STZ- and HFD-induced diabetic rats

As represented in Table 1, body weights of animals in all groups were performed at the initial and end of the study. Body weight of animals was significantly $(\mathrm{p}<0.05)$ maintained in all treatment groups (glibenclamide $5 \mathrm{mg} / \mathrm{kg}$ p.o., orlistat $60 \mathrm{mg} / \mathrm{kg}$ p.o., and [10]-gingerol 15 and $30 \mathrm{mg} / \mathrm{kg}$ p.o. during the study as compared to the control group).

Effect of [10]-gingerol on blood glucose level in STZ- and HFDinduced diabetic rats

A blood glucose level of animals in all groups was recorded at the $0^{\text {th }}$, $8^{\text {th }}$, and $21^{\text {st }}$ days. Progressive decrease in blood glucose level was found in all treatment groups during the study. At the end of experiment, glibenclamide $5 \mathrm{mg} / \mathrm{kg}$ p.o., orlistat $60 \mathrm{mg} / \mathrm{kg}$ p.o., and [10]-gingerol 15 and $30 \mathrm{mg} / \mathrm{kg}$ p.o. treated group blood glucose level decreased significantly $(\mathrm{p}<0.05)$ at the $21^{\text {st }}$ day, as represented in Table 2 .

Effect of [10]-gingerol on lipid profile level in STZ- and HFDinduced diabetic rats

In orlistat (60 mg/kg), glibenclamide (5 mg/kg), and [10]-gingerol 15 and $30 \mathrm{mg} / \mathrm{kg}$ p.o. treated group, i.e., TC, TG, and TP were significantly $(p<0.05)$ decreased as compared with the control group as shown in Table 3. Furthermore, there was significantly $(\mathrm{p}<0.05)$ increased in HDL level in all treatment groups when compared with the control group.

Effect of [10]-gingerol on SGOT and SGPT in STZ- and HFD-induced diabetic rats

After end days of the experiment, SGOT and SGPT levels were significantly $(\mathrm{p}<0.001)$ elevated in the diabetic control group. As shown in Table 4, in [10]-gingerol $15 \mathrm{mg} / \mathrm{kg}$ and $30 \mathrm{mg} / \mathrm{kg}$ treated group, SGOT and SGPT were significantly decreased ( $<<0.01$ ). In $5 \mathrm{mg} / \mathrm{kg}$ p.o. glibenclamide and $60 \mathrm{mg} / \mathrm{kg}$ p.o. orlistat-treated group, SGOT and SGPT were significantly decreased $(\mathrm{p}<0.001)$ as compared with the control group.

\section{Histopathological analysis}

The histopathological illustration showed normal acini and normal cellular population in the islets of Langerhans in the pancreas of vehicletreated rats (Fig. 1a). General damage to the islets of Langerhans and reduced dimensions of islets (Fig. $1 \mathrm{~b}$ ) and restoration of the normal

Table 1: Mean body weight change

\begin{tabular}{llll}
\hline Group & Drug & Dose & Body weight (g) \\
\cline { 2 - 3 } & & & Onset of study \\
\hline I & Normal & $1 \%$ Tween 80 & $210.15 \pm 8.83$ \\
II & Control & $1 \%$ Tween 80 & $220.20 \pm 10.00$ \\
III & Glibenclamide & $5 \mathrm{mg} / \mathrm{kg} \mathrm{p.o.}$ & $230.22 \pm 8.26$ \\
IV & Orlistat & $60 \mathrm{mg} / \mathrm{kg} \mathrm{p.o.}$ & $230.17 \pm 7.09$ \\
V & [10]-gingerol & $15 \mathrm{mg} / \mathrm{kg} \mathrm{p.o.}$ & $232.15 \pm 6.00$ \\
VI & [10]-gingerol & $30 \mathrm{mg} / \mathrm{kg} \mathrm{p.o.}$ & $230.10 \pm 5.00$ \\
\hline
\end{tabular}

Values are expressed as mean \pm S.E.M. ( $n=6$ ). Values are statistically significant at $\mathrm{p}<0.05$ versus control group, respectively (one-way ANOVA followed by Dunnett's test)

Table 2: Antidiabetic activity of [10]-gingerol on blood glucose level in STZ- and HFD-induced diabetic rats

\begin{tabular}{lllll}
\hline Groups & Treatment & Dose & \multicolumn{2}{c}{ Blood glucose (mg/dl) } \\
\cline { 3 - 4 } & & & Day 0 & Day 8 \\
\hline I & Normal & $1 \%$ Tween 80 & $80.00 \pm 4.00$ & $85.00 \pm 4.00$ \\
II & Control & $1 \%$ Tween 80 & $290.00 \pm 7.00$ & $387.00 \pm 9.60^{\#}$ \\
III & Glybenclamide & $5 \mathrm{mg} / \mathrm{kg} \mathrm{p.o.}$ & $105.00 \pm 5.00$ \\
V & Orlistat & $60 \mathrm{mg} / \mathrm{kg} \mathrm{p.o.}$ & $246.00 \pm 6.40$ & $128.00 \pm 6.50^{* *}$ \\
VI & [10]-gingerol & $15 \mathrm{mg} / \mathrm{kg} \mathrm{p.o.}$ & $250.00 \pm 6.00$ & $145.10 \pm 7.00^{*}$ \\
VII & {$[10]$-gingerol } & $30 \mathrm{mg} / \mathrm{kg} \mathrm{p.o.}$ & $255.00 \pm 5.50$ & $157.00 \pm 7.86^{*}$ \\
\hline
\end{tabular}

Values are expressed as mean \pm S.E.M. ( $n=6$ ). Values are statistically significant at $\mathrm{p}<0.05$ versus negative control group, respectively (one-way ANOVA followed by Dunnett's test) 
Table 3: Effect of [10]-gingerol on lipid profile level in STZ- and HFD-induced diabetic rats

\begin{tabular}{|c|c|c|c|c|c|c|}
\hline Group & Drug & Dose & Total cholesterol (mg/dl) & Triglyceride (mg/dl) & HDL (mg/dl) & TP (g/dl) \\
\hline I & Normal & 1\% Tween 80 & $80.50 \pm 5.50$ & $75.00 \pm 8.00$ & $51.87 \pm 1.13$ & $75.00 \pm 8.00$ \\
\hline II & Control & 1\% Tween 80 & $190.0 \pm 5.00$ & $137.5 \pm 6.50$ & $27.48 \pm 2.87$ & $135.50 \pm 6.50$ \\
\hline III & Glibenclamide & 5 mg/kg p.o. & $115.0 \pm 5.00 * * *$ & $83.00 \pm 9.00 * *$ & $49.78 \pm 2.03^{* *}$ & $80.00 \pm 9.00^{* * *}$ \\
\hline IV & Orlistat & $60 \mathrm{mg} / \mathrm{kg}$ р.o. & $109.00 \pm 3.60^{* * *}$ & $80.00 \pm 9.00 * *$ & $50.78 \pm 2.03^{* * *}$ & $83.00 \pm 5.50 * * *$ \\
\hline V & [10]-gingerol & 15 mg/kg p.o. & $130.0 \pm 5.00 * *$ & $96.00 \pm 7.00 *$ & $36.10 \pm 1.90^{*}$ & $95.50 \pm 5.00 * *$ \\
\hline VI & [10]-gingerol & 30 mg/kg p.o. & $121.5 \pm 4.50 * *$ & $86.50 \pm 5.50 *$ & $45.00 \pm 1.37 * *$ & $85.00 \pm 7.00^{* * *}$ \\
\hline
\end{tabular}

Values are expressed as mean \pm S.E.M. (n=6). Values are statistically significant at $P<0.05$ (one-way ANOVA followed by Dunnett's test)

Table 4: Effect of [10]-gingerol on SGOT and SGPT in STZ- and HFD-induced diabetic rats

\begin{tabular}{lllll}
\hline Group & Drug & Dose & SGOT (IU/L) & SGPT (IU/L) \\
\hline I & Normal & $1 \%$ Tween 80 & $57.00 \pm 5.00$ & $45.00 \pm 5.00$ \\
II & Control & $1 \%$ Tween 80 & $120.5 \pm 7.50$ & $115.0 \pm 10.00$ \\
III & Glibenclamide & $5 \mathrm{mg} / \mathrm{kg}$ p.o. & $68.50 \pm 4.50^{* *}$ & $58.00 \pm 4.00^{* *}$ \\
IV & Orlistat & $60 \mathrm{mg} / \mathrm{kg} \mathrm{p.o.}$ & $63.50 \pm 4.50^{* *}$ & $55.00 \pm 4.00^{* *}$ \\
V & {$[10]$-gingerol } & $15 \mathrm{mg} / \mathrm{kg} \mathrm{p.o.}$ & $78.50 \pm 5.50^{*}$ & $70.50 \pm 2.50^{*}$ \\
VI & {$[10]$-gingerol } & $30 \mathrm{mg} / \mathrm{kg}$ p.o. & $70.50 \pm 5.50^{*}$ & $62.50 \pm 6.50^{* *}$ \\
\hline
\end{tabular}

Values are expressed as mean \pm S.E.M. $(n=6)$. Values are statistically significant at $\mathrm{p}<0.05$ (one-way ANOVA followed by Dunnett's test). SGOT: Serum glutamic-oxaloacetic transaminase

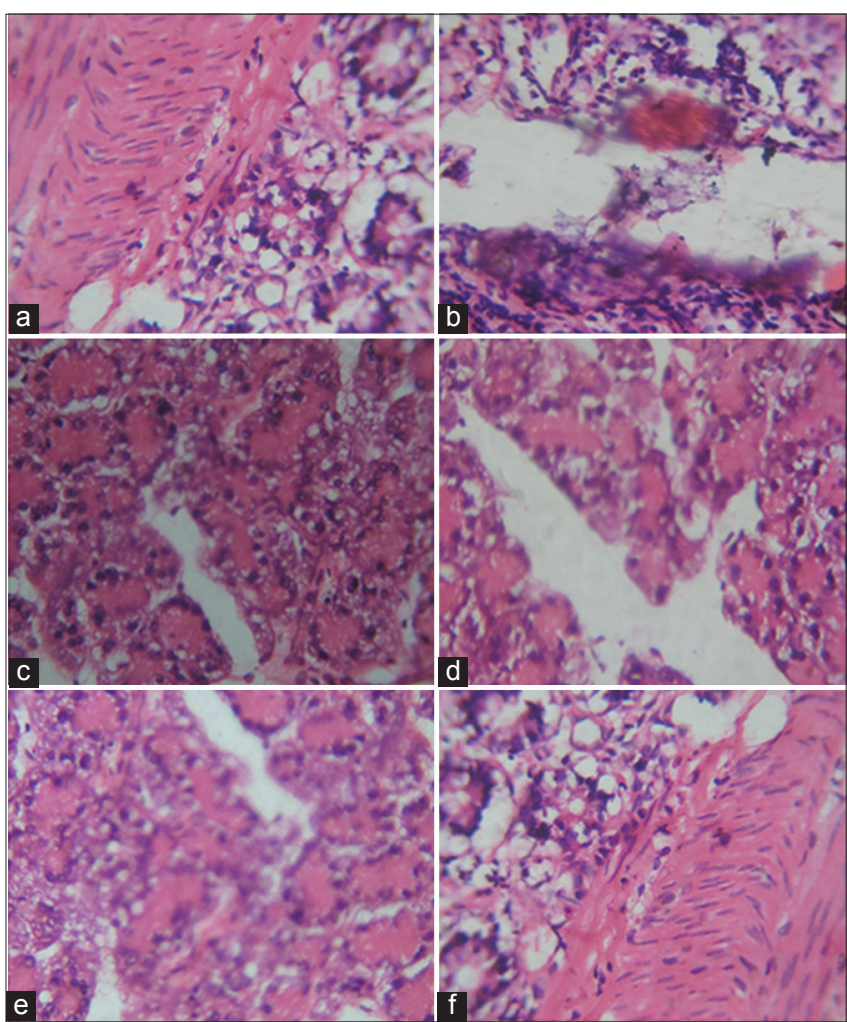

Fig. 1: Effect of drugs on pancreatic histopathology of diabetic rats (a) Normal, (b) control, (c) glibenclamide, (d) orlistat, (e) [10]-gingerol (15 mg/kg), (f) [10]-gingerol (30 mg/kg)

cellular population size of islets with hyperplasia by glibenclamide (Fig. 1c) were also shown. The partial restoration of the normal cellular population and enlarged size of $\beta$-cells with hyperplasia were shown by [10]-gingerol (15 and $30 \mathrm{mg} / \mathrm{kg}$; Fig. 1d-f).

In the present study, the effects of [10]-gingerol on diabetes were assessed using STZ- and HFD-induced diabetic rat model. The administration of [10]-gingerol for 21 days resulted in a significant reduction in blood glucose levels and lipid profile. The observed antihyperglycemic effect of [10]-gingerol is supported by our previous report of ginger [10].

The data obtained from this study showed that the treatment of [10]-gingerol, glibenclamide, and orlistat protects the diabetic rats from massive body weight loss when given orally. [10]-gingerol, glibenclamide, and orlistat-treated rats showed a recovery in final body weight which was close to that of normal control rats. Moreover, the weight gain was lesser in the diabetic rats when compared $(p<0.05)$ to normal control rats. Thus, the body weight loss due to catabolic effects seen in diabetic rats was only partially attenuated by all treatment groups, respectively. The decrease in body weight in diabetic rats could be due to dehydration and catabolism of fats and proteins [11].

Reports concerning the role of [10]-gingerol in connection with blood glucose level are not available in literature and our study is the first to report that [10]-gingerol attenuates the effect of blood glucose level. The blood glucose levels observed in the present study revealed a significant effect of [10]-gingerol on blood glucose level in STZ- and HFD-induced diabetic rats during the 3 weeks of the treatment period. Diabetic rats had significantly lowered $(\mathrm{p}<0.01)$ blood glucose levels, whereas [10]-gingerol-treated diabetic rats had significantly $(\mathrm{p}<0.01)$ increased blood glucose levels.

[10]-gingerol treatment was able to improve the lipid profile in STZ- and HFD-induced diabetic rats. Results of the histopathological changes in STZ- and HFD-induced type 2 diabetic rats, such as hepatic lipid accumulation and fatty degeneration, are consistent with the results of the lipid profile level. Treatment of diabetic rats with [10]-gingerol showed a considerable reduction in hepatic lipid accumulation. Lipase functions as a lipolytic enzyme that hydrolyzes TGs and phospholipids in circulating plasma lipoproteins. Reduction of fat absorption by the inhibition of pancreatic lipase is known to be beneficial for the regulation of obesity and related metabolic disorders [12].

The increase in blood sugar is accompanied by the increase in TC, TG, LDL, very low-density lipoprotein (VLDL), and fall of HDL. It is well known that in uncontrolled type 2 diabetes mellitus, there will be an increase in TC, TG, LDL, VLDL, and TG with a decrease in HDL which contributes to the coronary artery disease [13]. However, the treatment of [10]-gingerol associated with reduced the elevated levels of TC, TG, LDL, and VLDL as compared to control in diabetic animals at the $21^{\text {st }}$ day. There was an increase in HDL also, which indicates that [10]-gingerol may be beneficial to diabetic individuals with atherosclerosis since superior HDL level is associated with the lowered risk of the development of atherosclerosis in diabetes mellitus [14].

Oral administration of [10]-gingerol for 21 days to diabetic rats decreased their food consumption and improved body weight. This could be due to better control of the hyperglycemic state in the diabetic rats. Decreased blood glucose could improve body weight in STZ- and HFD-induced diabetic rats. During diabetes mellitus, the excess glucose present in the blood leads to glycation of tissue proteins $[15,16]$. Administration of [10]-gingerol to diabetic rats significantly $(\mathrm{p}<0.05)$ decreased the level of blood glucose. In diabetes mellitus, a variety of proteins are subjected to non-enzymatic glycation and this is thought to contribute to the long-term complications of the disease [17]. 
Diabetes mellitus is also associated with hyperlipidemia with a profound alteration in the concentration and composition of lipid [18]. Changes in the concentrations of the lipid with diabetes mellitus contribute to the development of vascular disease $[19,20]$. Fatty acids, an important component of cell membranes, are eicosanoid precursors and are, therefore, required for both the structure and function of every cell in the body [21]. STZ was significantly increased TL, TC, TG, FFA, phospholipids, LDL, and VLDL levels. The abnormally high concentration of serum lipids in diabetes mellitus is mainly due to an increase in the mobilization of free fatty acids from the peripheral fat depots since insulin inhibits the hormone-sensitive lipase. The marked hyperlipidemia that characterizes the diabetic state may, therefore, be regarded as a consequence of the uninhibited actions of lipolytic hormones on the fat depots [22]. Excess of fatty acids in the plasma produced by STZ promotes the liver conversion of some fatty acids to phospholipids and cholesterol.

Administration of [10]-gingerol to STZ- and HFD-induced diabetic rats produced a significant reduction in serum lipid profile, suggesting its potential in the prevention of hyperlipidemia and obesity. During the experimentation, Wistar rats did not show any mortality or any other adverse effects when the rats fed orally with [10]-gingerol at the doses of 15 and $30 \mathrm{mg} / \mathrm{kg}$. Thus, the [10]-gingerol has a good periphery of safety. Furthermore, all diabetic-treated groups showed histopathological changes of varying degree of alveolar histiocytosis due to phospholipidosis.

Diabetes is the second most common cause of death and different types of oral hypoglycemic agents are available for its treatment but none offers complete glycemic control. The side effect of taking insulin and oral hypoglycemic agents has brought about a growing interest for alternative traditional herbal medicine [23]. Herbal medicine is prepared from various plant parts to contain many bioactive compounds used primarily for treating [24]. The present study showed that [10]-gingerol exhibits significant insulin secretion and $\beta$-cells regeneration as well as antioxidant activity in experimental rats. Thus, a sufficient supply of antioxidants may prevent or delay $\beta$-cells dysfunction in diabetes by protecting against glucose toxicity. Moreover, antioxidant activity regulates glucose homeostasis through a multitude of actions. Further studies are in progress to isolate the active principle and elucidate the exact mechanism of the action of [10]-gingerol.

\section{CONCLUSIONS}

The findings indicated that the usefulness of the [10]-gingerol STZ- and HDF-induced diabetic rats. Our study suggested that [10]-gingerol dose dependently produced antidiabetic activity. This study might be helpful to understand the role of [10]-gingerol in the clinical treatment of diabetes mellitus.

\section{AUTHORS' CONTRIBUTIONS}

The authors declare that this work was done by the author named in this article.

\section{CONFLICTS OF INTEREST}

The authors declare that they have no conflicts of interest.

\section{REFERENCES}

1. Shetty P. Public health: India's diabetes time bomb. Nature 2012;485:S14-6.

2. Srinivasan K, Viswanad B, Asrat L, Kaul CL, Ramarao P. Combination of high-fat diet-fed and low-dose streptozotocin-treated rat: A model for Type 2 diabetes and pharmacological screening. Pharmacol Res 2005;52:313-20.

3. Bhandaria U, Chaudharia HS, Khannab G, Najmi AK. Antidiabetic effects of Embelia ribes extract in high fat diet and low dose streptozotocin-induced Type 2 diabetic rats. Front Life Sci 2013;7:186-96.

4. Palou M, Sánchez J, Rodríguez AM, Priego T, Picó C, Palou A, et al. Induction of NPY/AgRP orexigenic peptide expression in rat hypothalamus is an early event in fasting: Relationship with circulating leptin, insulin and glucose. Cell Physiol Biochem 2009;23:115-24.

5. Hamann A, Matthaei S. Regulation of energy balance by leptin. Exp Clin Endocrinol Diabetes 1996;104:293-300.

6. Flier JS. Obesity wars: Molecular progress confronts an expanding epidemic. Cell 2004;116:337-50.

7. Mohamed GA, Ibhramin SR, Elkhayat ES, Dine RS. Natural antiobesity agent. Bull Fac Pharm Cairo Univ 2014;52:269-84.

8. Zhang F, Ma N, Gao YF, Sun LL, Zhang JG. Therapeutic effects of 6-gingerol, 8-gingerol, and 10-gingerol on dextran sulfate sodiuminduced acute ulcerative colitis in rats. Phytother Res 2017;31:1427-32.

9. Soliman AM. Potential impact of Paracentrotus lividus extract on diabetic rat models induced by high fat diet/streptozotocin. J Basic Appl Zool 2016;77:8-20.

10. Khandouzi N, Shidfar F, Rajab A, Rahideh T, Hosseini P, Mir Taheri M, et al. The effects of ginger on fasting blood sugar, hemoglobin a1c, apolipoprotein B, apolipoprotein a-I and malondialdehyde in Type 2 diabetic patients. Iran J Pharm Res 2015;14:131-40.

11. Wang J, Ryu HK. The effects of Momordica charantia on obesity and lipid profiles of mice fed a high-fat diet. Nutr Res Pract 2015;9:489-95.

12. Birari RB, Bhutani KK. Pancreatic lipase inhibitors from natural sources: Unexplored potential. Drug Discov Today 2007;12:879-89.

13. Arvind K, Pradeepa R, Deepa R, Mohan V. Diabetes and coronary artery disease. Indian J Med Res 2002;116:163-76.

14. Taskinen MR. Diabetic dyslipidemia. Atheroscler Suppl 2002;3:47-51

15. Nagarajan NS, Murugesh N, Thirupathy Kumaresan P, Radha N, Murali A. Antidiabetic and antihyperlipemic effects of clemeo felina. Fitoterapia 2005;76:310-5.

16. Pari L, Saravanan R. Antidiabetic effect of diasulin, a herbal drug, on blood glucose, plasma insulin and hepatic enzymes of glucose metabolism in hyperglycaemic rats. Diabetes Obes Metab 2004;6:286-92.

17. Luo Q, Cai Y, Yan J, Sun M, Corke H. Hypoglycemic and hypolipidemic effects and antioxidant activity of fruit extracts from Lycium barbarum. Life Sci 2004;76:137-49.

18. Vlassara H, Brownlee M, Cerami A. Nonenzymatic glycosylation of peripheral nerve protein in diabetes mellitus. Proc Natl Acad Sci U S A 1981;78:5190-2.

19. Ahmed RG. The physiological and biochemical effects of diabetes on the balance between oxidative stress and antioxidant defense system. Med J Islam World Acad Sci 2005; 15:31-42.

20. Odetola AA, Akinloye O, Egunjobi C, Adekunle WA, Ayoola AO. Possible antidiabetic and antihyperlipidaemic effect of fermented Parkia biglobosa (JACQ) extract in alloxan-induced diabetic rats. Clin Exp Pharmacol Physiol 2006;33:808-12.

21. Nikkilä EA, Kekki M. Plasma triglyceride transport kinetics in diabetes mellitus. Metabolism 1973;22:1-22.

22. Howard BV, Savage PJ, Bennion LJ, Bennett PH. Lipoprotein composition in diabetes mellitus. Atherosclerosis 1978;30:153-62.

23. Saad EA, Hassanien MM, Hagrasy MA, Radwan KH. Antidiabetic, hypolipidemic and antioxidant activities and protective effects of Punica granatum peels powder against pancreatic and hepatic tissues injuries in streptozotocin induced IDDM in rats. Int J Pharm Pharm Sci 2015;7:397-402.

24. Arumugam S, Natesan SK. Hypoglycemic effects of Barleria noctiflora fractions on high fat fed with low dose streptozotocin induced Type-2 diabetes in rats. Int J Pharm Pharm Sci 2016;8:193-200. 